Snežana Milinković ${ }^{*}$

Università di Belgrado

\title{
Zogović, Mirka (2007). Barok: književna teorija i praksa [Teoria e prassi del barocco letterario]. Beograd: Narodna knjiga
}

\begin{abstract}
Affidati per la stampa alla prestigiosa "Narodna knjiga" ed ospitati dalla collana "Novi kontekst" [Nuovi contesti], gli studi di M. Z. vertono - com'è facile intuire sin dal titolo - su tematiche legate alla letteratura barocca, e vengono, in tal senso, a costituire il giusto, se non doveroso coronamento delle precedenti indagini intorno alla presenza di G. Marino nella poesia ragusea (Marino i dubrovačka književnost, Matica srpska, Novi Sad, 1995). L'intento è quello di offrire un inquadramento, teorico-letterario oltre che metrico-stilistico, della produzione barocca in lingua italiana, sondata con l'ausilio di tracciati e prospettive di molteplice reperimento, pur senza rinunciare a raccomandare una preferenza per quelle impostazioni che - secondo le avvertenze dell'A., articolate già nelle annotazioni introduttive - si ritengono più adeguate a penetrarne o, se si vuole, a "recepirne" l'intimo costrutto.

Di quali preferenza si tratti, lo si chiarisce subito, prendendo in esame la Književno-teorijska misao baroka u Italiji XX veka (pp. 11-29), vale a dire le concezioni teoriche di matrice novecentesca: muovendosi tra Benedetto Croce da un lato e quanti, dall'altro, hanno (arditamente) insistito sull'opportunità di rivestire il barocco di un abito post-moderno, l'A. non esita a sollecitare una decisa virata in direzione del Tesauro e dei suoi degni interlocutori, ai quali va riconosciuto l'indubbio merito di avere introdotto ed elaborato gli strumenti e le categorie interpretative che assicurano un accesso "disincantato" alla materia, ossia capace di non farsi irretire da facili allusioni a presunte sintonie con i simulacri della contemporaneità. Non è un caso, dunque, che l'attenzione si sposti, nelle pagine successive, su quella che è da considerare la figura retorica per eccellenza del poeta-
\end{abstract}

*snezana.milinkovic@fil.bg.ac.rs 
re barocco e delle concezioni linguistiche che lo contraddistinguono: la "metafora di Tesauro", vista attraverso le lenti del suo Cannocchiale aristotelico, con l'obiettivo di coglierne i tratti che le sono inerenti, come la magnificenza, l'acutezza, il concettismo (Tezaurova metafora kao primer baroknog promišljanja pesničkog jezika, pp. 30-57). Nel terzo ed ultimo intervento della prima sezione si pongono invece a confronto l' "obscuritas" nella poetica barocca e 1" "ostranenie" nella poetica del formalismo russo ("Obscuritas" u baroknoj $i$ "ostranenie" u poetici ruskog formalizma, pp. 59-72), con l'esplicito proposito di verificare la plausibilità di nessi e parallelismi sul piano procedurale, di là dalle insopprimibili specificità, attestate dalle differenze di impianto teorico.

La seconda parte del libro consta di tre capitoli: Intertekstualnost $u$ baroknoj verziji Đambatiste Marina [L'intertestualità nella versione barocca di Giambattista Marino], pp. 75-82; "Vrt zadovoljstva" u "Adonisu": primer Marinove intertekstualne prakse ["Il giardino del piacere" nell" "Adone": esempio di prassi intertestuale in G. Marino], pp. 83-94; Marinova pisma kao model barokne epistolografije [Le lettere di Marino come modello di epistolografia barocca], pp. 95-130. Vi si mettono a fuoco quei procedimenti che riflettono il dialogo con i registri di anteriore fattura e ai quali l'ottica novecentesca attribuisce i connotati dell' "intertestualità", nelle cui pieghe va rinvenuto, secondo l'A., il significato più profondo dell'opera del Marino e della sensibilità barocca in generale. Nelle lettere del Marino si individua, oltretutto, il punto di passaggio tra l'epistola pubblica e la lettera privata, attraverso il quale si approda alla società moderna.

I contributi in chiusura di volume sono entrambi dedicati a questioni di metrica, e si rivolgono sia alla "prassi poetica del Barocco" in generale (Metrika barokne poetske prakse, pp. 133-143), che, più specificatamente, all'originalità del "verso nel madrigale del Marino" (Stih u Marinovom madrigalu, pp. 144-150). 